\title{
SOCIABILIDAD Y ALIMENTACIÓN. ESTUDIO DE CASOS EN LA TRANSICIÓN AL SIGLO XIX EN EL VIRREINATO DEL RÍO DE LA PLATA
}

MARSCHOFF, MARÍA ${ }^{\mathrm{I}}$

La tesis doctoral "Sociabilidad y Alimentación. Estudio de casos en la transición al siglo XIX" fue financiada por una beca doctoral otorgada por el CONICET (20052010) y calificada con 10 (Sobresaliente). Con el título que aquí indicamos ha sido aceptada para su publicación en la South American Archaeology Series de British Archaeological Reports (Internacional Series), Archaeopress, Oxford, Reino Unido, editado por el Dr. A. D. Izeta. Las investigaciones en uno de los casos de estudio abordados, la colonia española de Floridablanca, fueron posibles gracias a los siguientes subsidios, dirigidos por la Dra. M. X. Senatore: "Arqueología de la Modernidad" UBACyT F453 (2008-2010), “Tiempos Modernos en Patagonia" de Fundación Antorchas (20042007), "Arqueología de la Sociedad Moderna en Antártida y Patagonia Meridional" del Programa IM40 de la Agencia Nacional de Promoción Científica y Tecnológica SeCyT (2002-2005).

\section{INTRODUCCIÓN}

Esta investigación pretendió aportar a la historización del proceso a través del cual se constituyó la dicotomía entre "lo público" y "lo privado". Esa distinción comienza a ocurrir en la vida cotidiana de las sociedades occidentales entre los siglos XVII y XVIII cuando algunas experiencias diarias de la gente comienzan a adoptar una cualidad más pública en contraposición a otras vivencias que se perciben "como si" fueran más privadas (Chartier 1991; Goodman 1992; Habermas et al. 1974; Perrot 1990). Si bien puede argüirse que todas las sociedades y personas experimentaron, y experimentan, esta dicotomía en su accionar cotidiano, fue durante ese período que en nuestra sociedad en particular esta oposición comenzó a adoptar las características con las que hoy la definimos y que nos resultan completamente naturales.

Esta distinción en la vida cotidiana resulta fundamental para otro nivel en el cual se piensa la separación entre público y privado, fundamental en la constitución del Estado moderno: el nacimiento de la denominada “esfera pública" (Habermas 1991). Muchos investigadores han presentado diferentes estudios y teorías alrededor de la constitución de la esfera pública, su relevancia para el nacimiento del Estado moderno y las características que adoptó en diferentes contextos particulares -ver, por ejemplo, Chartier (1991), González Bernaldo (2007), Gordon (1989), Habermas (1991), Myers (1999), Uribe-Uran (2000), Van Horn Melton (2004), Velasco Moreno (2000).

\footnotetext{
I CONiCet - Departamento Científico de Antropología, Facultad de Ciencias Naturales y Museo, Universidad Nacional de La Plata,
} ARGENTINA・E-MAIL: mmarschoff@hotmail.com 
El punto en común que existe entre la mayoría de estos autores es remitir el origen de los cambios en este nivel a las prácticas cotidianas (Ariès 1992; Chartier 1991; Goodman 1992; Habermas 1991). En ese nivel las experiencias de "lo público" y "lo privado" se modifican en un mundo material y en interacción con otros seres humanos, es decir en la sociabilidad. Es por ello que constituyen el eje de esta tesis. Uno de los factores principales que cambia estas experiencias, y cuya influencia se incrementa a partir del siglo XVI, es la conciencia de la mirada del otro sobre la propia vida (Elias 1987, 1996). Es decir que con el tiempo la importancia de la presencia de otras personas y su injerencia en las conductas de uno se vuelve esencial: quiénes participan en ciertas actividades y quiénes no, quiénes las presencian, por medio de qué objetos se llevan a cabo y en qué contexto son todas cuestiones que comienzan a ser reglamentadas. Estos cambios son los que definían y aún hoy definen qué es público y qué es privado, para quién y en qué contexto.

Diversos aspectos de esta compleja problemática comenzaron a ser estudiados principalmente a partir de la década de 1950 generando una amplia bibliografía de referencia. Sin embargo, por la propia dinámica e historia de estas disciplinas y por el predominio y mayor accesibilidad a los autores europeos y estadounidenses el panorama del estado de las investigaciones muestra varios sesgos, actualmente muy discutidos (Gordon 1992; Jacob 1994; Klein 2002; Lynch 1994; Nathans 1990; Uribe-Uran 2000). Siguiendo la línea planteada por esta bibliografía crítica, mencionamos aquí principalmente tres debilidades u omisiones en el corpus de investigaciones sobre la constitución de "lo público" y "lo privado". En primer lugar, que estos cambios, tanto en la vida cotidiana como en relación a la constitución de la esfera pública, suelen ser descritos y analizados únicamente entre las elites. Estos grupos son postulados, de manera intencional o no, como los generadores de innovaciones que luego son adopta- das de forma más o menos pasiva por el resto de la sociedad. En segundo lugar, estas investigaciones fueron llevadas a cabo utilizando como casos a grupos de Francia, Inglaterra y Alemania, lugar de origen de la mayoría de los autores revisados. España, Rusia, Portugal y sus colonias, son considerados casos especiales, "marginales" al proceso, y en donde las innovaciones generadas en los países "centrales" eran incorporadas principalmente por la voluntad de la autoridad pública -en los ejemplos mencionados se trataba de monarquías ilustradas. Finalmente, y en estrecha relación con este segundo sesgo, la "manifestación" en las regiones "marginales" de este proceso adopta las características de una "incorporación por difusión" que a su vez suele ser caracterizada como tardía, o al menos posterior al momento de surgimiento de estos cambios en los contextos considerados "centrales".

Los objetivos que se plantearon en esta tesis apuntaron justamente a estas debilidades y pretendieron analizar el surgimiento de experiencias cotidianas que diferenciaron entre público y privado en casos de estudio particulares que no pertenecían a estos contextos centrales y entre grupos que no constituían las elites de las sociedades a las que pertenecían. Los casos elegidos fueron el Puerto de Buenos Aires durante el período en que funcionó como cabecera de Virreinato (1776-1810) y la Nueva Colonia y Fuerte de Floridablanca entre el momento de su fundación en la costa patagónica a fines de 1780 y su abandono en enero de 1784. En los dos casos nos centramos en el estudio de la vida cotidiana abordada desde su materialidad intentando conocer la forma que se constituían experiencias diferenciales de "lo público" y "lo privado" en la sociabilidad del día a día. Sin embargo, de este amplio universo que es la cotidianeidad realizamos dos recortes metodológicos puntuales. En primer lugar, nos ocupamos exclusivamente de las experiencias cotidianas que tenían lugar en el ámbito doméstico, es decir en el o los recintos en donde una o más personas habitaban y el contexto 
de objetos, actividades y relaciones sociales que se entablan en este tipo de espacios. El segundo recorte que realizamos fue al interior de este contexto, ya que nos ocupamos únicamente de aquéllos que se estructuran alrededor de la alimentación en el ámbito doméstico.

\section{RESULTADOS OBTENIDOS EN AMBOS CASOS DE ESTUDIO}

Las líneas de evidencia utilizadas para abordar la materialidad de la forma de organizar la alimentación cotidiana en los ámbitos domésticos fueron distintas en cada caso de estudio. Para Buenos Aires utilizamos documentos escritos, en particular los inventarios de bienes inmuebles y objetos que se realizaban cuando una persona moría y se iniciaba el proceso de su herencia -inventarios post mortem depositados en el Archivo General de la Nación de los cuales se revisó más del 90\% de los legajos disponibles. Tras una estricta crítica, tanto interna como externa de cada documento, se seleccionó una muestra de 100 inventarios que abarcan el período que va de 1776 a 1810 cada uno de los cuales constituye una unidad de análisis.

A partir de las listas de objetos relacionados a la alimentación que se inventariaron en cada ámbito doméstico se realizaron diversos análisis estadísticos -análisis de clusters, correlaciones, análisis de distribuciones con técnica de reemuestreo o bootstrap, entre otros. En primer lugar se logró diferenciar al interior de la muestra dos grupos con formas de preparar y cocinar los alimentos diferentes y dos conjuntos cuyos stocks de bienes mostraron maneras de presentar y consumir las comidas distintas entre sí. Ambos agrupamientos no eran independientes estadísticamente, por lo que se pudo asociar formas de preparar y cocinar los alimentos con maneras de presentarlos y consumirlos. Sin embargo, estos grupos con formas de organizar la alimentación distintas no pudieron vincularse de manera significativa con otras características de la unidad doméstica, tales como la composición del grupo de cohabitación, la ocupación de la unidad doméstica, el origen del difunto, su sexo y su nivel de riqueza patrimonial.

En segundo lugar, se analizó la vinculación existente entre ciertas tendencias novedosas de la alimentación en el momento en Europa con los grupos identificados en la muestra y sus formas de organizar la alimentación. Estas tendencias a una mayor separación entre las personas y las actividades, a un reconocimiento del gusto individual, a la enfatización del aspecto visual de las comidas, entre otras, impulsaban sociabilidades diferenciadas según el grado de formalización del evento de consumo de alimentos. Los resultados mostraron que en la manera de preparar y cocinar los alimentos estas nuevas modas no sólo se hallaban presentes en los grupos de la muestra y dan cuenta de su definición como conjuntos con prácticas diferentes, sino que también se mantuvieron estables, a pesar del claro aumento en la disponibilidad de artefactos que ocurre durante la mayor apertura comercial del período virreinal. En cambio, en lo que respecta a las formas de presentar y consumir los alimentos, los grupos identificados en la muestra no parecen seguir las tendencias europeas de cambios en las prácticas alimenticias, sino que siguen un derrotero propio marcado por una clara preferencia por los consumos informales de alimentos, las denominadas bebidas sociales, entre las cuales se destaca con gran fuerza la amplia y creciente aceptación del mate.

El caso de Floridablanca fue trabajado principalmente desde la evidencia arqueológica proveniente de cuatro sectores excavados en este sitio los cuales corresponden a parte del recinto de habitación del Superintendente de la colonia, a dos habitaciones que conformaban una pulpería, a un único recinto de la unidad doméstica de un soldado y su mujer y a cuatro habitaciones que constituían la vivienda de una familia de labradores. Estas unidades de habitación han sido ampliamente trabajadas en el marco del proyecto 
"Arqueología e Historia en la colonia española de Floridablanca" dirigido por la Dra. M. $\mathrm{X}$. Senatore.

A partir del análisis de la arquitectura y del uso del espacio, de la distribución de hallazgos, del estudio de la evidencia que aportan los restos de vidrio y cerámica relacionables a las prácticas alimenticias y de macrorrestos vegetales y restos arqueofaunísticos buscamos comprender cómo se llevaban a cabo las diferentes actividades relacionadas con la alimentación en cada unidad. De este modo pudimos observar que cada unidad organizó su alimentación de forma diferente. Así, en el caso de la pulpería se pudo observar que el consumo de alimentos era una actividad privada y no habría formado parte de la oferta de este establecimiento y al mismo tiempo se segregaron las actividades de preparación y cocción. En el recinto de habitación del Superintendente también estas actividades se hallaban separadas y el consumo era primordialmente individual con un énfasis en la presentación de los alimentos y la formalización las cuales indican el grado de publicidad que se le quiso imprimir a este tipo de eventos. En cambio, en el recinto que constituía la vivienda de un soldado y su mujer, las actividades de la alimentación no separaban grupos de sociabilidad ni hay evidencia de que se hayan puesto en práctica estrategias de publicización o privatización y, al mismo tiempo, se observó una limitada accesibilidad a la diversidad de productos y circuitos de circulación de la colonia lo cual indicaría un grupo cerrado en sí mismo. En la vivienda de labradores las actividades de preparación y cocción se hallaban separadas del consumo el cual presentó características que nos llevan a pensar que habrían existido dos formas distintas de sociabilidad, una privada al grupo de corresidencia y otra que habría incluido personas ajenas al mismo.

Así, al igual que ocurría en otros contextos contemporáneos, incluidos los europeos, en ambos casos de estudio se pudo observar que la sociabilidad organizada alrededor de la alimentación comenzaba a ser un elemento im- portante en la constitución de la identidad del grupo que habitaba la unidad doméstica. A través de esas prácticas los grupos que conformaban la unidad doméstica mostraron formas diferentes y muy diversas de establecer los límites internos y externos de "lo privado" y "lo público" hacia el interior y el exterior de los mismos. También se hizo patente una característica muy propia de los contextos coloniales ya que las formas de organizar la alimentación hispanocriollas tendieron a la coexistencia de un reconocimiento de la heterogeneidad de las personas en cuanto a gustos individuales, privados, con prácticas que buscaban eliminar los límites privados del consumo en el momento público de la alimentación.

Ninguna de las diversas formas de organizar la alimentación identificadas, así como tampoco el período histórico en el fueron observadas, nos estarían indicando que estas sociedades coloniales se encontraban "al margen” de lo que ocurría en otros contextos. Al contrario, lo que el estudio de casos mostró es que las elecciones tomadas fueron hechas a partir de un conocimiento de otros contextos, en una negociación cotidiana en donde las preferencias propias, consideradas importantes para la unidad doméstica, eran un criterio de peso.

El objetivo central de la Tesis es definir y caracterizar las tradiciones alfareras, que se materializan en estilos tecnológicos, de las sociedades que habitaron distintas eco-zonas del bolsón de Fiambalá y la puna cordillerana de Chaschuil (Dpto. Tinogasta, Catamarca) entre los años 1350-500 AP aproximadamente. Se busca conocer las elecciones técnicas realizadas por los alfareros durante la producción de los objetos, investigando aquéllas que han quedado manifiestas en las vasijas terminadas

\section{BIBLIOGRAFÍA}

ARIÈS, P.

1992 Para una historia de la vida privada. En Historia de la Vida Privada. El Proceso de 
Cambio en la Sociedad de los Siglos XVIXVIII, dirigido por P. Ariès y G. Duby, pp. 7-19. Taurus, Madrid.

CHARTIER, R.

1991 The Cultural Origins of the French Revolution. Duke University Press, Durham and London.

ELIAS, N.

1987 El Proceso de la Civilización. Investigaciones Sociogenéticas y Psicogenéticas. Fondo de Cultura Económica, México.

1996 La Sociedad Cortesana. Fondo de Cultura Económica, México.

GONZALEZ BERNALDO, P.

2007 Civilidady Politica en los Orígenes de la Nación Argentina. Las Sociabilidades de Buenos Aires, 1829-1862. Fondo de Cultura Económica, Buenos Aires.

GOODMAN, D.

1992 Public sphere and private life: toward a synthesis of current historiographical approaches to the old regime. History and Theory 31(1): 1-20.

\section{GORDON, D.}

1989 "Public opinion" and the civilizing process in France: the example of Morellet. Eighteenth-Century Studies 22(3): 302-328.

1992 Philosophy, sociology, and gender in the enlightenment conception of public opinion. French Historical Studies 17(4): 882911.

\section{HABERMAS, J.}

1991 The Structural Transformation of the Public Sphere. An Inquiry into a Category of Bourgeois Society. MIT Press, Cambridge, Massachusetts.

HABERMAS, J., S. LENNOX y F. LENNOX

1974 The public sphere: an encyclopedia article (1964). New German Critique 3: 49-55.

JACOB, M.C.

1994 The mental landscape of the public sphe- re: a European perspective. EighteenthCentury Studies 28(1): 95-113.

KLEIN, L.E.

2002 Politeness and the interpretation of the British eighteenth-century. The Historical Journal 45(4): 869-898.

LYNCH, K.

1994 The family and the history of public life. Journal of Interdisciplinary History 24(4): 665-684.

MYERS, J.

1999 Una revolución en las costumbres; las nuevas formas de sociabilidad de la elite porteña, 1800-1860. En Historia de la Vida Privada en la Argentina. Tomo 1. País Antiguo. De la Colonia a 1870, dirigido por F. Devoto y M. Madero, pp. 110-145. Taurus, Buenos Aires.

NATHANS, B.

1990 Habermas`s "public sphere" in the era of the French Revolution. French Historical Studies 16(3): 620-644.

PERROT, M.

1990 Introduction. En A History of Private Life. Volume 4. From the Fires of Revolution to the Great War, dirigido por P. Ariès $\mathrm{y}$ G. Duby, pp. 1-5. The Belknap Press of Harvard University Press, Cambridge, Massachusetts.

URIBE-URAN, V. M.

2000 The birth of a public sphere in Latin America during the Age of Revolution. Comparative Studies in Society and History 12(2): 425-457.

VAN HORN MELTON, J.

2004 The Rise of the Public in Enlightenment Europe. Cambridge University Press, Cambridge.

VELASCO MORENO, E.

2000 Nuevas instituciones de sociabilidad: las academias de finales del siglo XVII y comienzos del XVIII. Cuadernos Dieciochescos 1: 39-55. 
